TERRA. Revista de Desarrollo Local e-ISSN: 2386-9968

Número 6 (2020), 396-401

DOI 10.7203/terra.6.17650

IIDL - Instituto Interuniversitario de Desarrollo Local

\title{
Reseña. Gobernanza colaborativa para la inclusión social. Una experiencia de investigación y acción participativa
}

\author{
María Raquel Agost-Felip \\ Profa. Titular Área de Psicología Social (Universitat Jaume I de Castellón, España) \\ ragost@uji.es \\ https://orcid.org/0000-0002-5111-1937
}

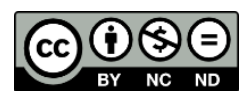

Esta obra se distribuye con la licencia Creative Commons Reconocimiento-NoComercial-SinObraDerivada 4.0 Internacional 


\section{SECCIÓN RESEÑAS}

\section{Reseña. Gobernanza colaborativa para la inclusión social. Una experiencia de investigación y acción participativa}

Resumen. Esta obra permite conocer una experiencia de trabajo colaborativo, dirigida a implementar una nueva gobernanza en el ámbito de la inclusión social en Gipuzkoa. La sistematización del proceso mediante la metodología de la Investigación Acción Participativa, invita a redefinir sinergias e impulsar procesos participativos, en los que la administración aporta la capacidad de rediseñar las políticas públicas y los servicios sociales, el tercer sector social la atención a las personas que viven en situación de exclusión social en el territorio, y la universidad la metodología y la sistematización. Un trabajo desarrollado a lo largo de tres años (2016-2018) y organizado en tres ágoras como espacios de coconstrucción de conocimiento compartido y de trabajo en red.

Palabras clave: Gobernanza colaborativa, inclusión social, investigación y acción participativa (IAP), servicios sociales, políticas públicas.

Recibido: 14 de junio de 2020

Devuelto para revisión: -

Aceptado: 14 de junio de 2020

\section{Referencia / Citation:}

Agost-Felip, M. R. (2020). Reseña. Gobernanza colaborativa para la inclusión social. Una perspectiva de investigación y acción participativa. TERRA. Revista de Desarrollo Local, (6), 396-401. DOI 10.7203/terra.6.17650 


\title{
Ane Ferran Zubillaga, Cinta Guinot Viciano, Asun Berasategui Otegi (Ed.) \\ GOBERNANZA COLABORATIVA PARA LA INCLUSIÓN SOCIAL. UNA EXPERIENCIA DE INVESTIGACIÓN Y ACCIÓN PARTICIPATIVA
}

\author{
Madrid (España), Catarata, 2019. 206 páginas.
}

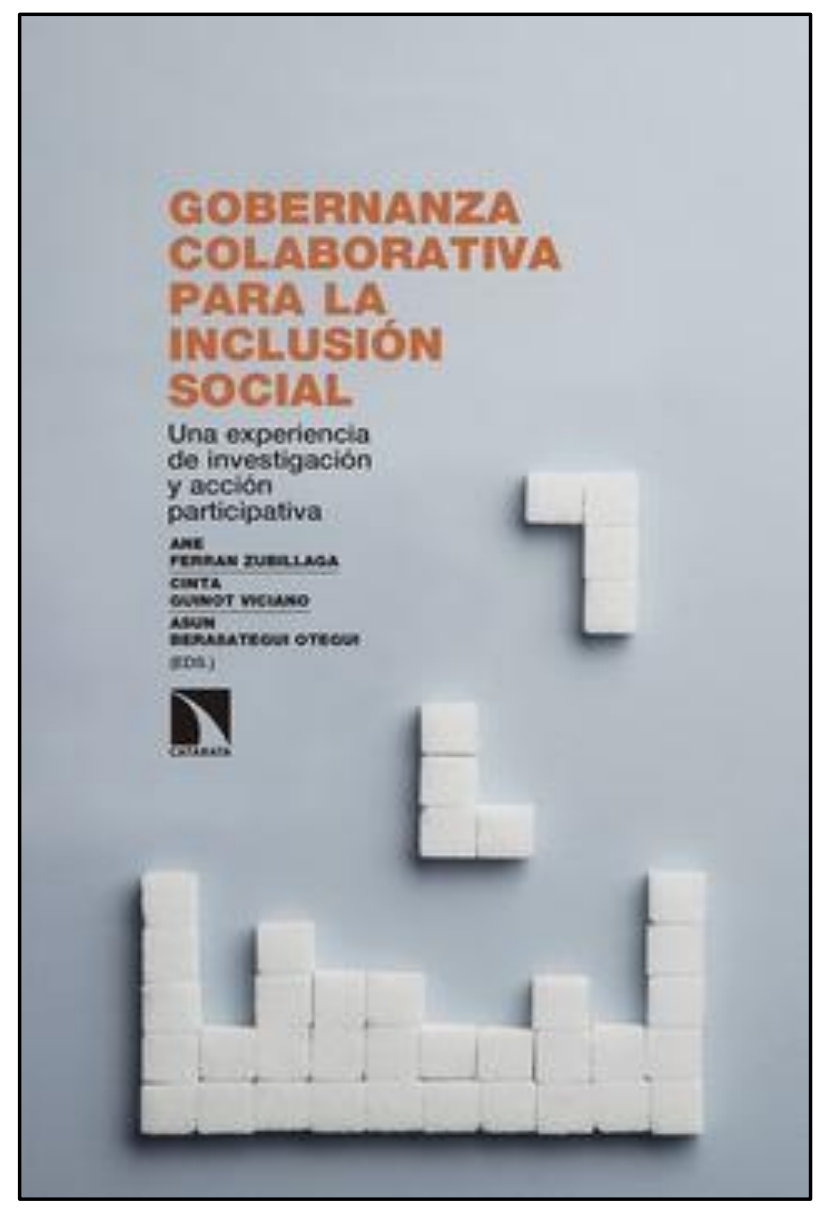

Esta obra permite conocer una experiencia de trabajo colaborativo, dirigida a implementar una nueva gobernanza en el ámbito de la inclusión social en Gipuzkoa. La sistematización del proceso mediante la metodología de la Investigación Acción Participativa, invita a redefinir sinergias e impulsar procesos participativos, en los que la administración aporta la capacidad de rediseñar las políticas públicas de servicios sociales, el tercer sector social la atención a las personas que viven en situación de exclusión social en el territorio, y la universidad la metodología y la sistematización. Un trabajo desarrollado a lo largo de tres años (2016-2018) y organizado ágoras como espacios de coconstrucción de conocimiento compartido y de trabajo en red.

El trabajo consta de tres grandes bloques con identidad propia, que pueden abordarse de manera independiente, según los intereses de las personas lectoras. Previo a estas tres partes encontramos un capítulo introductorio, donde se presenta la motivación y la propuesta institucional de la Diputación Foral de Gipuzkoa de abordar la acción de gobierno desde un modelo de gobernanza abierto y cooperativo. Esta acción se desarrolla, en el marco del Plan Etorkizuna Eraikiz (construyendo el futuro) y el Plan de Inclusión Social Elkar-EKIN, con el que se pretenden organizar las diferentes políticas sectoriales desarrolladas por las instituciones públicas y entidades del tercer sector, en torno a la exclusión social de manera coordinada y colaborativa.

La primera parte del libro denominada "el contexto", aborda los aspectos más teóricos de conceptualización y metodología para avanzar en la gobernanza colaborativa en inclusión. El capítulo 1 aborda las bases conceptuales de la inclusión social, así como la relación entre exclusión-inclusión entendida como un continuo, esta dualidad implica articular procesos de cambio integral en los diferentes ámbitos de la vida de las personas. Elementos que se recogen en la normativa del Gobierno Vasco Ley 12/1998 contra la Exclusión Social y en las Leyes de Servicios Sociales donde el derecho a la inclusión ha sido una constante en el marco normativo. El sistema desarrollado ha representado un avance de las políticas públicas para abordar la inclusión social, sin embargo, plantea el reto de ampliar y reforzar estas políticas públicas de inclusión. 


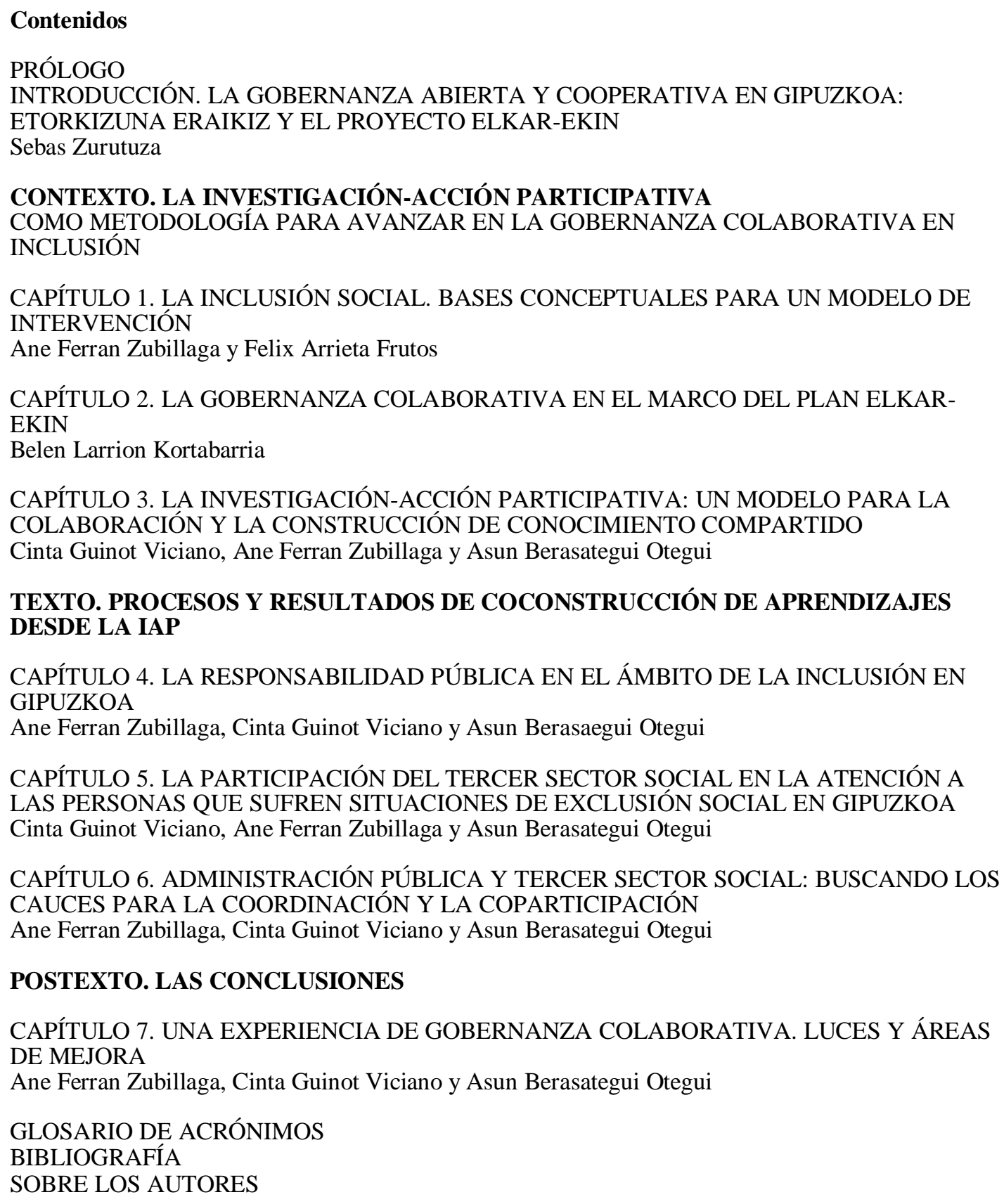

El capítulo 2 explica la gobernanza colaborativa del Plan de Inclusión Social Elkar-EKIN, liderado por la Diputación Foral en el marco de una planificación autonómica y territorial, una experiencia que intenta evitar duplicidades en el sistema de servicios sociales y evaluar resultados. Un trabajo de tres años en continua adaptación, basado en: la decisión y apuesta política; la experimentación y creación de propuestas a partir de las oportunidades que brindan los marcos estratégicos y normativos; el fomento de actitudes hacia la gobernanza colaborativa. El capítulo 3 presenta la metodología utilizada en este proceso, en el que se ha utilizado la Investigación Acción Participativa (IAP) para desarrollar un trabajo colaborativo que permita la construcción de conocimiento compartido, siempre con el impulso de un grupo motor. Para ello, en el seno del proyecto Elkar-EKIN se conforman tres ágoras o espacios de reflexión y trabajo conjunto (capítulos 4, 5 y 6). Otro elemento clave en esta experiencia ha sido la tarea de 
sistematización y la elaboración de documentos, tal y como se detalla en este capítulo con el trabajo desarrollado por el equipo de investigación de la universidad, fruto de ello es la elaboración de esta publicación.

La segunda parte denominada "el texto", presenta el desarrollo del proceso diseñado con la metodología de Investigación Acción Participativa. Contiene tres capítulos donde se exponen los resultados de las ágoras. El capítulo 4 se estructura a partir de la experiencia de la administración pública como responsable de la inclusión social en Gipuzkoa (nivel de atención primaria y secundaria de servicios sociales). Se presenta un análisis del proceso de acceso de una persona al sistema de servicios sociales, donde se recogen las dificultades que presenta el sistema (temporalidad de las citas, ratios de atención, espacios de atención o dificultades de comunicación con personas extranjeras). Esta reflexión no solo se centra en los procedimientos establecidos y en la cartera de servicios, si no que plantea la importancia de no perder de vista la centralidad de la persona. Se destaca por parte de las y los profesionales la necesidad de la existencia de foros y espacios de conversación como las ágoras que faciliten un trabajo colaborativo para mejorar la atención. El capítulo 5 aborda la participación del tercer sector en la atención a las personas que sufren situaciones de exclusión social en el territorio, en el caso de Gipuzkoa casi todos los recursos de atención del ámbito de la exclusión están gestionados por entidades del tercer sector (TSS). También se presentan buenas prácticas del TSS en el ámbito de la inclusión. Junto a este análisis se presenta el diagnóstico de las necesidades del sistema, como la respuesta a nuevos perfiles o la atención de las personas en situación de exclusión grave. Un elemento clave que subyace en este análisis es la necesidad de superar un sentimiento de compartimentalización de los recursos. El capítulo 6 presenta el trabajo conjunto de ambas partes, en el que se diseñan alternativas de coordinación y coparticipación en el abordaje de la inclusión social, se corresponde con la tercera ágora desarrollada en 2018 en la que confluyen los trabajos realizados en 2016 y 2017 por las ágoras anteriores (capítulos 4 y 5). Los actores reflexionan a partir del trabajo previo, sobre los puntos en común, la necesidad de coordinar mejor el sistema de servicios sociales y la atención a las personas en situación de vulnerabilidad, para evitar la fragmentación de procesos y garantizar la continuidad de la atención a las personas entre los agentes implicados. Se diseña una propuesta como experiencia piloto que se debe implementar en el periodo 2019-2020. También se identifican los recursos necesarios para poner en marcha la experiencia: contar con una herramienta en común, contar con espacios de coordinación, contar con recursos de apoyo a la persona que se encuentra en el proceso de valoración, avanzar en el lenguaje común, garantizar el respaldo político, sistematizar y evaluar la experiencia, se requiere una supervisión externa del proceso, así como un compromiso personal de los profesionales e institucional y elaborar un "libro de Ruta".

La tercera parte del libro denominada "el postexto", presenta las conclusiones del trabajo, se corresponde con el capítulo 7, en el que se evalúa la experiencia durante los tres años que recoge el proceso. En él se aprecia la complejidad del trabajo realizado en el que han participado 52 entidades públicas y privadas y 100 personas, que han trabajado en el proceso de IAP, a través de los espacios colaborativos (ágoras). La valoración de la experiencia es positiva, se ha realizado de manera sistematizada analizando tanto los espacios de colaboración, como los resultados obtenidos y las fortalezas, se recogen los testimonios en primera persona de los y las participantes y también los aspectos a mejorar. En la última parte de este capítulo se presentan las reflexiones del grupo de investigadoras facilitadoras de la Universidad de Deusto que han acompañado y sistematizado esta experiencia. 
La estructura del libro permite una aproximación desde diferentes ámbitos, tanto del teórico como del aplicado. Se sientan las bases teóricas y metodológicas para abordar el proceso colaborativo de diagnóstico y transformación del sistema de inclusión social, aplicando la metodología de la Investigación Acción Participativa. La gobernanza colaborativa requiere de una sistematización y de un proceso basado en el compromiso y la constancia, no en la inmediatez, como demuestra esta experiencia que se ha desarrollado durante tres años.

En la introducción se presenta el marco institucional en el que se promueve el Plan de Inclusión Social Elkar-EKIN, con el objeto de diseñar una política pública a partir de un modelo de gobernanza colaborativa, ante la necesidad de afrontar un futuro incierto y cambiante, en un mundo complejo, nada más cercano a nuestra realidad actual en la etapa post-COVID. Se destaca el papel de la investigación y la aportación de la universidad cuya función ha sido acompañar y dinamizar el proceso a través de la metodología de la Investigación Acción Participativa, todo un ejemplo de transferencia. La obra se estructura en tres bloques: el Contexto, donde se presentan las bases teóricas del proceso. El Texto, en el que se expone la experiencia participativa de las tres ágoras de trabajo entre los sectores de atención en los servicios sociales (diputación, servicios sociales, tercer sector) y la universidad. El Postexto, en el que se presentan las conclusiones del trabajo, así como, la valoración de la experiencia y las lecciones aprendidas. Un capítulo necesario para conocer realmente la incidencia y las consecuencias del proceso participativo, con sus luces y sus sombras, que pueden ilustrar a otros territorios como referencia del camino a seguir.

Es una obra colectiva fruto de las aportaciones de los agentes participantes en el proceso de construcción de una nueva gobernanza en el ámbito de la inclusión social del territorio. Un trabajo colaborativo, en el que confluyen varios factores facilitadores, el diseño de un proceso de Investigación Acción Participativa como apuesta transformadora, el desarrollo temporal ajustado al diseño de un proceso participativo de estas características (tres años en este caso), la confluencia de los diferentes agentes (administración pública, tercer sector, instituciones), la aportación de la ciencia a través de la universidad (metodología, sistematización y facilitación) y la dotación de recursos necesarios.

Más allá de la experiencia en sí, este trabajo nos muestra las potencialidades de implementar un proceso participativo que es en sí mismo transformador, en el que se genera conocimiento compartido y propuestas dirigidas a mejorar la atención de las personas más vulnerables, con el objeto de proponer una hoja de ruta común entre los diferentes agentes que facilite la inclusión social.

María Raquel Agost-Felip

Profa. Titular Psicología Social

Instituto Interuniversitario de Desarrollo Local (IIDL)

Universitat Jaume I de Castelló (España)
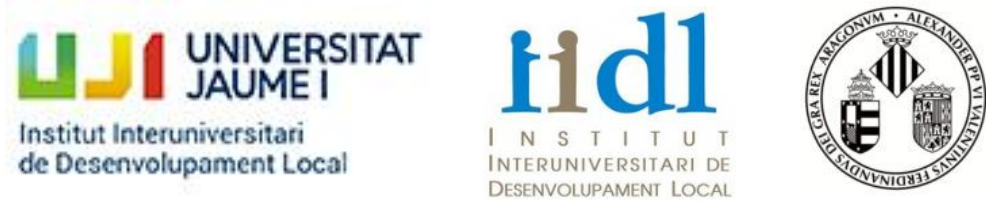